\title{
OVERCOMING BARRIERS TO COLLABORATIVE CONCEPTUALIZATION IN COGNITIVE THERAPY WITH OLDER ADULTS
}

\author{
Georgina Charlesworth and Sally Greenfield \\ North East London Mental Health Trust, UK
}

\begin{abstract}
This is the third in a series of three papers on cognitive therapy formulation with older people. The aims of this paper are to identify barriers to collaborative conceptualization, and to summarize useful strategies for overcoming these barriers. Obstacles to collaborative conceptualization with older clients have previously been thought of as a consequence of age-related skills deficits. In this paper we focus instead on the barriers created by therapistand client-held prejudicial beliefs. A social cognitive perspective is used to conceptualize stereotypical prejudices. Strategies are described for challenging or reframing prejudicial beliefs, and addressing the mechanisms that perpetuate these beliefs.
\end{abstract}

Keywords: Collaboration, conceptualization, formulation, older adults, prejudice, stereotyping.

\section{Introduction}

You lot [therapists] can only deal with the stuff that's in the head; my problem is physical. You see, my family have always been a poorly lot... it's in the genes! My Dad died aged 69 and his brother at 70 - it's as if we've got a timer in us. Listen I don't want to be rude, but you just can't help. I'm too tired and too depressed to fight this now. My only hope is to find a "proper" doctor to see if he can work wonders with some new fangled treatment.

68-year-old male client on first consultation

A core principle of cognitive therapy is that there should be "collaborative effort" between the therapist and the client, in which clients weigh empirical evidence rather than be persuaded by argument or debate. Ideally, the therapist will guide the client to collect information in which the unhelpful cognitions are embedded. The client and therapist will then work together to examine the resulting pool of data, develop a conceptualization and plan intervention strategies (Beck \& Emery, with Greenberg, 1985, p. 182). Thus collaborative empiricism (Burns \& Beck, 1978) directs the formulation process, providing a rationale for specific interventions. Collaboration makes interventions meaningful and relevant to the client, thus facilitating engagement (Cameron, 1978). The quality of collaboration is significantly related to outcome, across all modalities of treatment not just cognitive therapy (Krupnick et al., 1996).

Reprint requests to Georgina Charlesworth, Lecturer in Clinical \& Health Psychology of Old Age, Centre for Behavioural and Social Sciences in Medicine, University College London, Wolfson Building, 48 Riding House Street, London W1W 7EY, UK. E-mail: g.charlesworth@ucl.ac.uk 
Dick, Gallagher-Thompson and Thompson (1996) "cannot stress enough how the success of $\mathrm{c} / \mathrm{b}$ [cognitive behavioural] therapy hinges on the collaborative therapeutic relationship" (p. 522). However, the formation of a collaborative relationship is not always straightforward. Clients "sent" for therapy, as is the case with a significant proportion of older clients, may be neither welcoming of a psychological rationale nor looking for a collaborative relationship. The 68-year-old gentleman quoted above had strongly held beliefs about his disorder. He did not see the purpose of psychological treatment, he was not looking to form a collaborative partnership with the therapist, and his views would not make him an ideal candidate for cognitive therapy (see Safran, Segal, Shaw, \& Vallis, 1990). The vignette may be familiar to cognitive therapists working with older people, and it highlights some key questions that the current paper intends to address, namely (i) what are the obstacles to working collaboratively and (ii) how can obstacles be overcome?

Barriers to collaboration arise with people of all ages, and indeed challenges to collaboration have been discussed in the "disorder-specific" cognitive therapy literature: for example, in the areas of psychosis (Chadwick, Birchwood, \& Trower, 1996; Fowler, Garety, \& Kuipers, 1998a, b; Gumley \& Power, 2000; Kinderman \& Lobban, 2000; John \& Turkington, 1995), eating disorders (Kleifield, Wagner, \& Halmi, 1996), substance abuse (Beck, Wright, \& Newman, 1992; Liese, 1994), personality disorders (Layden, Newman, Freeman, \& Morse, 1993) and chronic pain (Hanlon, Turk, \& Rudy, 1987).

Commonly arising obstacles to collaboration in cognitive therapy with older people include: facilitating active involvement with clients who expect to be passive recipients of care; working to a cognitive model with clients who hold a "non-cognitive" theory of cause or maintenance of their presenting problems; and making complex conceptualizations understandable and meaningful for clients with reduced cognitive capacity. We take the view that both therapist and client factors can form barriers to collaboration, and the initial case example illustrated the potential for mismatch between therapists' and clients' expectations and/or abilities. Both therapists and clients are likely to become aware of such mismatches and attribute meaning to them. Collaboration will be prevented or disrupted if the client's attributions arise from stereotypical prejudices towards "the young", "therapists" or "therapy". Alternatively, the therapist's stereotypical views of the aged may result in him/her blaming the client for being "unable to engage in therapy", "un-psychologically minded" or "cognitively impaired".

In order to work collaboratively, it is important for the therapist to become cognizant of their own cognitive biases, and those of the client. Proponents of social cognition theories have previously identified that clinicians may be susceptible to stereotypes of older adults in ways that lessen their ability to provide competent treatment (Yarhouse, 2000, p. 122). Based on the social cognition approach, we propose that barriers to collaborative conceptualization with older clients can arise from stereotypical prejudice of younger therapists towards their older clients and vice versa.

\section{Stereotypical prejudice model}

We propose a model of the formation and maintenance of stereotypical prejudice towards, and by, older people in therapy. The model provides a conceptualization of cognitive barriers to collaboration, and follows the basic cognitive premise that beliefs arise from prior experiences and are reinforced by cognitive and other processes. In outlining the model, we begin by identifying three categories of prejudicial belief. We consider the client and therapist 


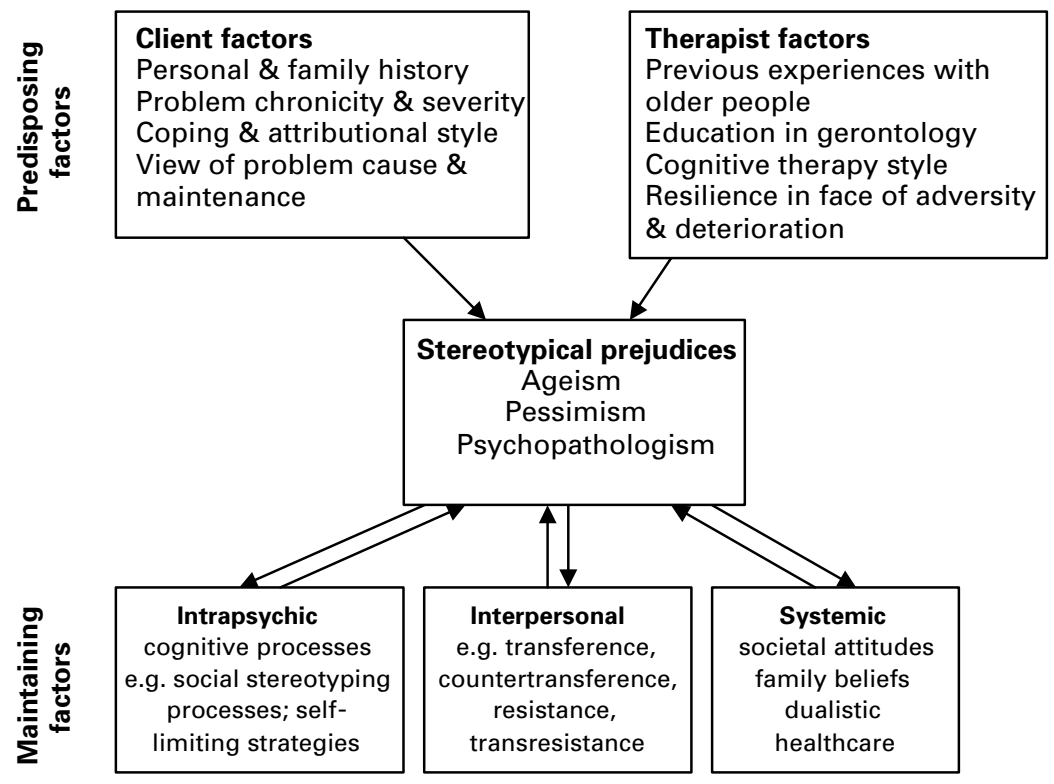

Figure 1. Model of predisposing and perpetuating factors in the formation and maintenance of stereotypical prejudices in cognitive therapy with older people

experiences that are likely to give rise to such beliefs. We then describe three mechanisms of belief maintenance, namely clients' and therapists' cognitive processes, relationship factors, and systemic issues. A diagrammatic representation of the model is shown in Figure 1.

\section{Stereotypical prejudices}

In the cognitive prejudice model we include three commonly occurring, but unhelpful, categories of client and therapist prejudices, namely "ageism", "pessimism towards therapy" and "psychopathologism". These categories are not mutually exclusive, and there may be overlap. Typical examplars are shown in Table 1.

Ageism. The phenomenon of ageism is pervasive in many Western societies (see Blytheway, 1994; Nelson, 2002). Ageist views of the young towards the old, or the old towards themselves (internalized ageism), typically label "the old" as being unable to change, unable to respond to psychological therapies, and on a course of deterioration rather than continued growth. Some older clients may show reverse ageism towards the young, including their therapists; for example, they may view younger cohorts as uncaring, unable to understand, or as too vulnerable to be exposed to the harsh realities of the world.

Pessimism towards therapy. "Therapeutic nihilism" has long been identified as a common but unhelpful position for therapists when it comes to working with older people. Consequently, older people have often been excluded from therapy. Pessimism in the therapist can be triggered by their own beliefs that "nothing can be done", or by a sense of helplessness or hopelessness in an older client. Therapist and client pessimism are likely where depression is seen as a 
Table 1. Stereotypical prejudices that can act as barriers to collaboration

\begin{tabular}{lc}
\hline Client beliefs & Therapist beliefs \\
\hline Ageism (internalized, or towards young) & Ageism (towards the old, or self ) \\
"I'm too old to change" & "The old" can't do cognitive work/take a \\
"You can't teach an old dog new tricks" & psychological perspective/do homework or \\
"They (the therapist) are too young & behavioural experiments" \\
to understand" & "I'm too young/inexpert to help" \\
Pessimism (helplessness/hopelessness) & Pessimism (helplessness/hopelessness) \\
"I'm dying - talking can't save me" & "All their NATs are realistic - there \\
& is nothing I/therapy can do" \\
Psychopathologism & Psychopathologism \\
"I've been sent to therapy so I must & "They've been referred to me, so \\
be mad" & they must have a mental illness" \\
& "All symptoms are best explained by \\
& psychological factors" \\
\hline
\end{tabular}

natural and inevitable consequence of common late-life experiences (e.g. chronic or terminal physical illness, caring for a chronically ill relative, loss of confiding relationships due to other's relocation, illness or death) or where depression is viewed as an expected and normal part of ageing. A review of pessimism in psychotherapy with older people is provided by Laidlaw, Thompson, Dick-Siskin and Gallagher-Thompson (2003, p. 21).

Psychopathologism. The term "psychopathologism" is used to refer to the belief that symptoms are best explained by intrapsychic factors, either proximal or distal, irrespective of evidence indicative of other potential explanations (e.g. physical, neurological, environmental). Inadvertent psychopathologism may arise where therapists fail to consider non-psychological explanations, for example, when therapists assume that patients referred for therapy for somatoform disorders have already been screened appropriately for possible physical causes of symptoms. Clients can also develop a belief that if they have been referred to therapy, then their difficulties must indeed be "all in the mind".

A subcategory of psychopathologism is a cognitive fundamentalist perspective. Here, the therapist believes that, de facto, a cognitive explanation is the most likely, and that clients must both be able to express their internal world in terms of thoughts and have a cognitive view of cause and maintenance. A client expressing a non-cognitive formulation, or using noncognitive language, is inappropriately seen as avoidant, unmotivated, uneducated or impaired.

\section{Predisposing factors}

Client and therapist factors, and the interaction between them, can predispose either party to stereotypical prejudices.

Client factors. Clients' views of ageing are likely to be influenced by society, media and their own experiences with older people. Their views on problem cause and maintenance, and their optimism for treatment and recovery, will be influenced by a range of features: personal and family history, direct and indirect experiences of physical and mental health, 
culture, education, religion, problem chronicity and severity, history of relapse, coping and attributional styles, experience of previous interventions, and, perceived mechanism of change.

Laidlaw and colleagues (2004) have described the importance of considering a broad range of contextual beliefs when conceptualizing problems with older clients. Beliefs likely to influence a client's motivation to engage in therapy include: cohort beliefs, such as expectations of custodial mental healthcare and the stigma of mental health difficulties; role investments (e.g. "I was always the person others turned to for help, now I'm useless"); health-related beliefs (e.g. "All old people lose their health, so I may as well give up").

Older people referred for therapy may have late-onset or lifelong difficulties. In either scenario, clients may be using strategies that protect the status quo, thus minimizing the risks associated with change (Leahy, 1999). For example, pessimism for therapy and nonengagement may arise as a self-protective stance against future failure, or against re-exposure to regrets from the past.

Therapist factors. Therapists' views of ageing are likely to be influenced by their experiences with older people (family and work), societal views, and education (or lack of this) in gerontology. Views on problem cause and maintenance, and optimism for treatment and recovery will be influenced by their therapeutic stance, experience, training and supervision, and their resilience in the face of adversity and deterioration.

Where training has been limited to a single framework or technique, a therapist may feel rapidly disempowered when working with older people. This can predispose the therapist to ageism, pessimism for therapy, or both. For example, therapists whose main tool is to identify and challenge thinking biases are likely to feel pessimistic about therapy if they appraise a client's negative automatic thoughts (NATs) as entirely realistic and in keeping with the objective evidence.

\section{Maintaining factors}

Cognitive processes. Stereotypes are maintained by inter-related cognitive processes such as categorization, role schemas, confirmation bias, illusory correlation and the base-rate fallacy (Yarhouse, 2000). Actual or perceived differences between younger therapists and older clients facilitate categorization, for example, through expectations of differing roles (role schemas). Once a perception has been formed, there is a tendency to abstract information that confirms one's perceptions (confirmation bias), associate whole cohorts with the negative behaviours of a few individuals (illusory correlation), and ignore base rate information in favour of individual cases or anecdotes (base-rate fallacy).

Interpersonal processes. Dick et al. (1996) highlight the importance of considering clienttherapist interactions in work with older adults (pp. 522-524), including transference - countertransference and resistance - trans-resistance phenomena. We suggest that such interactions can act to maintain stereotypical prejudices. For example, clients' accounts may trigger strong emotional responses in therapists (Genevay \& Katz, 1991) who identify with the possibility of similar events in their own future. Feeling overwhelmed can reinforce pessimism for therapy (e.g. "What can therapy do when a person's grandchild has just died?") Alternatively, overwhelmed therapists may take refuge in the view that "It's not the event, it's the appraisal, and this person is appraising their loss unhelpfully". The latter could be adaptive for the therapist, but risk giving clients the impression that "most people would handle this situation 
without difficulty, and you feel distressed because of your cognitive vulnerability factors". Unsurprisingly, clients may respond by feeling that the cognitive approach has little to offer.

Where therapists attempt to counter their own sense of helplessness by intervening early, by offering false hope or reassurance for example, a client may feel isolated and misunderstood. In such circumstances, effective collaboration is unlikely to develop. Similarly, unsolicited suggestions and advice can undermine a client's attempts to cope, and reinforce their view that they are indeed "going mad".

Systemic factors. Systemic factors such as societal attitudes, family responses and healthcare systems can also maintain stereotypical prejudices. Attitudes of referrers and family towards therapy can heavily influence client expectation. Discussion on societal attitudes is available elsewhere (e.g. Blytheway, 1994; Nelson, 2002), as is exposition of issues relating to family responses to illness (e.g. Rolland, 1989).

Healthcare systems can maintain stereotypical prejudicial beliefs through reinforcing the view of "elders as dependent", and as a consequence of a physical-mental health split in service organization that encourages "mind-body dualism" (Salmon, 2000). Psychologically distressed clients referred from physical to mental health services rarely fail to be given a psychiatric diagnosis such as a depressive or anxiety disorder. This is often the case, even in circumstances where normal age-related bodily variation has been mislabelled by the client as illness, and appraised by the referrer as a somatic presentation of psychological distress, or where clients have recently experienced major life events. Operating from a mind-body dualistic perspective can give the message "It's all in your mind" thus increasing a client's distress which in turn confirms a clinician's belief in a psychological cause (psychopathologism).

In summary, cognitive processes such as categorization and stereotyping have advantages in that they enable us to process an enormous amount of information without making too many demands on cognitive functioning (Yarhouse, 2000). However, ageism, pessimism for therapy and psychopathologism are barriers to client-therapist collaboration.

\section{Overcoming prejudice}

We now turn to methods for addressing stereotypical prejudices and the factors that maintain them. Given that the therapeutic relationship is a key part of the overall treatment process, especially when working with clients' complex issues (Bruch \& Bond, 1998), and that collaboration is a fundamental aspect of a good relationship (Beck, Rush, Shaw, \& Emery, 1979), we make the assumption that the reader already has the ability to form good therapeutic relationships. We also assume that he/she has the required level of competence to engage clients in cognitive therapy (see Padesky \& Greenberger, 1995). We focus particularly on addressing stereotypical prejudices in work with older people through challenging ageism, pessimism and psychopathologism.

\section{Challenging ageism}

Strategies for challenging ageism in therapists include: increasing gerontological knowledge; increasing exposure to "successful" elders; adapting therapy goals and processes to meet individuals' needs and circumstances. In addition, one can attempt to maximize therapeutic 
gains by ensuring accessibility to therapy. The latter strategies can also be used to challenge clients' internalized ageism.

Increasing gerontological knowledge. Education about normal ageing can challenge cognitive processes such as illusory correlation and the base-rate fallacy (Yarhouse, 2000). Dick and colleagues (1996) cite a review of adult development and ageing by Cavanaugh (1990) that provides strong support of the older adult's ability to adapt to new situations and learn new ideas. Literature on lifespan development provides information on developmental processes and stages (Santrock, 2002) that provide evidence against the view that ageing is associated with inevitable decline and depression. More recent literature on cognitive therapy has shown that older adults are able to make use of the approach (see Laidlaw et al., 2003 for a review), and indeed can show better outcome than their younger counterparts (Walker \& Clarke, 2001).

Therapists can also increase their knowledge by learning from their own clients (e.g. historical events, and changing societal expectations and norms). Learning from clients provides a context for understanding individuals, thus broadening and deepening the therapist's characterization of the client, and reducing the tendency to stereotype (Yarhouse, 2000). Learning from clients is implicit within guided discovery (Padesky, 1993), and can facilitate collaboration through acknowledging that clients bring areas of expertise to the relationship, challenging views of "therapist as expert helping dependent elder" (Zeiss \& Lewinsohn, 1986).

Increasing exposure to "successful" elders. As the clinical population of older adults is a self-selected sample, and not representative of the larger population of older adults, seeing more older clients in clinical practice may not reduce the tendency to stereotype (Yarhouse, 2000). Where possible, therapists should consider increasing their contact with older adults who are ageing successfully. In addition, therapists may find it useful to consider the strengths shown by their clients in coping with events throughout their long lives.

Adapt to needs and circumstances, not age. Much of the literature on cognitive therapy for older people includes recommendations for adaptation. However, older cohorts are arguably the most heterogeneous of all populations, and while major adaptations may be necessary for some individuals, they are not universally required. Woods and Charlesworth (2002) suggest that adaptations should not be made for age per se, but to meet individual needs. For example, changes may be appropriate for clients presenting with physical health problems (including sensory changes), cognitive deficits, self-limiting cohort beliefs, with a history of interventions and chronic adversity. It is relevant to note that each of these dimensions has relevance for people of all ages. They are not the exclusive preserve of the elderly.

Where difficulties are seen as being caused by age, intervention is limited by the selfevident truth that "I'll only get older". By re-framing difficulties in terms of individual need and circumstances, a range of interventions become available, aiming to challenge, rehabilitate, adapt, or compensate as appropriate.

Design for accessibility. One of the most effective ways for challenging a belief that "old people can't do therapy" is to experience therapeutic success. Numerous suggestions have been made for therapists to increase accessibility to cognitive therapy for people of all ages, and to maximize opportunities for success. Firstly, therapists follow the principles of good communication, paying attention to the way in which information is delivered, collected and processed. Delivery of information can be adapted in terms of vocabulary, style and content 
to match the knowledge and abilities of the listener. Rapport can be facilitated by using the client's own words rather than jargon, and by using descriptive rather than judgemental language (Padesky, 2002). Collaboration can be strengthened by asking questions that the client can answer (Padesky, 1993).

Secondly, therapists must either ensure that the client is equipped with the necessary cognitive skills, or make appropriate adaptations to compensate for client deficits. Explanations for terms such as "thoughts" and "emotions" should be given as necessary. Therapists can provide experiential rather than didactic education by listening out for examples of the client's points of view, opinions and beliefs, and labelling them as examplars of the term "thoughts". Similarly, education about the inter-connectedness of the mind and the body can be provided both didactically and experientially. Skills training exercises have been described elsewhere (e.g. Greenberger \& Padesky, 1995; Linehan, 1993).

Thirdly, therapists can "play to client's strengths" by matching tasks with abilities. For example, clients who use the language of body sensations to express their distress (rather than emotions or cognitions) are unlikely to complete self-monitoring thought diaries as an early homework task. However, they may be able to monitor activities and behavioural responses to distress along with ratings of symptom severity. Fourthly, therapists can reduce the cognitive demands of therapy. Adaptations to compensate for memory impairments include shortening sessions, regularly reviewing information, and providing written or taped information to support the spoken consultation (e.g. Dick et al., 1996). Cognitive load can also be reduced in formulation (see Charlesworth \& Reichelt, 2004).

Fifthly, therapists can facilitate the testing of alternative hypotheses or perspectives through fostering client's curiosity as to the precursors and consequences of their beliefs. Generally, people from older cohorts will have been exposed to changing societal attitudes and related behaviours. In addition, they are often able to reflect on the power of beliefs through considering the influence of, say, family or religious beliefs.

\section{Addressing pessimism}

Strategies for addressing pessimism include providing a rationale for cognitive therapy, ensuring emotional support and setting achievable goals.

Providing a rationale for therapy. Irrespective of the duration or cause of a client's symptoms or current predicament, a case can be made for the role of cognitions in a client's response to their situation, either in terms of triggering additional difficulties, or exacerbating existing symptoms. For example, for a physically ill client, a rationale for a psychological approach would be that physical symptoms lead to psychological consequences such as worry, fear, depression and anger and these emotions can trigger off further body sensations, thus making the situation even more difficult. Communicating the rationale to others may also help address systemic maintaining factors.

Ensuring emotional support. Stereotypical prejudices may protect the client or therapist against feeling overwhelmed by emotive issues such as chronic deteriorating illness and death. Feeling understood can help engender hope, and the therapeutic alliance is deepened when the client feels they are being heard. Therapy in adversity is facilitated by a compassionate approach that encourages the expression of emotion (Moorey, 1996). The therapist must feel supported (through supervision or other means) if they are to provide an appropriate level of 
compassion, maintain the balance between empathic identification and detachment (Strayer, 1987), and tolerate the nature and complexity of problems that some older adults bring (Dick et al., 1996, p. 518).

Setting achievable goals. Optimism for a good outcome in therapy is facilitated by a realistic delineation of what is possible for a psychological approach. In the context of chronic deteriorating and life-threatening illness, for example, appropriate goals may be to see a reduction in excess disability, and for the client to increase their sense of coping-efficacy. Setting achievable goals can increase hope and a client's sense of control.

\section{Addressing psychopathologism}

Strategies for addressing psychopathologism include revisiting the basic cognitive model, broadening CBT knowledge and skills, testing out assumptions and using non-pathological formulations.

Revisiting basic knowledge and broadening skills. The cognitive model of emotional disorders emphasizes the interactions between cognitive, somatic, behavioural, affective and other factors. Used in the social and environmental context of the individual, multiple mechanisms for cause and maintenance can be considered, without being limited to psychological-only, or cognitive-only conceptualizations. As the model has been developed, the realities of adverse circumstances have been emphasized. For example, CBT frameworks are now available for physical disability (Krantz, 1995; Rybarczyk et al., 1992), medical and surgical issues, including pain (e.g. Salmon, 2000), adverse life circumstances (Moorey, 1996) and life threatening illness (Liese \& Larson, 1995).

Test out assumptions. The dangers of making assumptions are well known in cognitive therapy, yet therapists remain at risk of operating as if their assumptive beliefs are valid. Therapists must examine the way in which their own thoughts and beliefs may be having a limiting effect both within sessions and over the course of treatment (Dick et al., 1996, p. 523; Laidlaw et al., 2003, p. 25; Padesky, 1998)

Use non-pathological formulations. Non-pathological formulations "normalize" distress and acknowledge clients' efforts to cope. Frameworks for non-pathological formulations include: adjusting to new circumstances [You are experiencing a whole range of emotional, cognitive and physiological reactions in response to difficult circumstances. They are common reactions to the kind of situation you find yourself in.]; a mis-match between current circumstances and previously adaptive coping strategies; and loss of positive reinforcers (Worth Enhancing Beliefs) rather than triggering of negative schema (James, Kendell, \& Reichelt, 1999).

In summary, there are numerous strategies available to help therapists, clients and others to become aware of, and challenge, prejudices against ageing and cognitive therapy with the elderly. The cognitive model is robust and flexible enough to acknowledge non-psychological factors in symptom development, allowing therapists to respond compassionately to client reactions to distressing events, while identifying and restructuring unhelpful cognitions. 


\section{Conclusion}

When faced with obstacles in collaborative conceptualization with older adults, therapists should be wary of making simple assumptions that the problems relate to skills deficits within their clients. Rather, they should consider the influences of their own prejudicial beliefs of ageing, their prejudices against therapy, and their therapy-limiting expectations that a cognitive-only explanation will encapsulate clients' views. Combating prejudice is an effortful process as new responses must be learned and practised like any habit (Devine, 1989; Yarhouse, 2000).

Before ending it is worth revisiting the story of the 68-year-old gentleman who did not initially want to engage in therapy. After some discussion he was recruited into treatment. $\mathrm{He}$ agreed to attend on the premise that, while a psychological therapy would not help him directly with his physical problems, it would be possible to work on the psychological consequences ("side-effects" or "by-products") of his physical difficulties. He agreed to do this, as he admitted that he was currently feeling depressed and this had led him to drop many of the activities he had previously enjoyed. He made steady progress over the course of 4 months, re-engaging in social activities and becoming more interpersonally fulfilled. However, a few weeks prior to the date of his planned discharge, he died. His death was one month after his 69th birthday.

\section{References}

Beck, A. T., \& Emery, G., With Greenberg, R. L. (1985). Anxiety disorders and phobias: A cognitive perspective. New York: Basic Books.

BeCK, A. T., Rush, A. J., Shaw, B. F., \& EMERY, G. (1979). Cognitive therapy for depression. New York: Guilford.

Beck, A. T., Wright, F., \& Newman, C. (1992). Cocaine abuse. In A. Freeman \& F. Dattilio (Eds.), The comprehensive casebook of cognitive therapy. New York: Plenum.

Blytheway, B. (1994). Ageism (Rethinking Ageing Series). Buckingham: Open University Press.

BRUCH, M., \& BOND, F. W. (1998). Beyond diagnosis: Case formulation approaches in CBT. Chichester: Wiley.

BURns, D. A., \& BECK, A. T. (1978). Cognitive behavior modification of mood disorders. In J. P. Foreyt \& D. P. Rathjen (Eds.), Cognitive behavior therapy: Research and application. New York: Plenum.

CAmeron, R. (1978). The clinical implementation of behavior change techniques: A cognitively oriented conceptualization of therapeutic "compliance" and "resistance". In J. P. Foreyt \& D. P. Rathjen (Eds.), Cognitive behavior therapy: Research and application. New York: Plenum.

CAvanaugh, J. C. (1990). Adult development and aging. Belmont: Wadsworth Publishing Co.

ChADWICK, P. D., BIRCHWOOD, M. J., \& TROWER, P. (1996). Cognitive therapy for delusions, voices and paranoia. Chichester: Wiley.

Charlesworth, G., \& Reichelt, K. (2004). Keeping conceptualizations simple: Examples with family carers of people with dementia. Behavioural and Cognitive Psychotherapy, 32, 401-409.

DEVINE, P. G. (1989). Stereotypes and prejudice: Their automatic and controlled components. Journal of Personality and Social Psychology, 56, 5-18.

Dick, L. P., Gallagher-Thompson, D., \& Thompson, L. W. (1996). Cognitive-behavioral therapy. In R. T. Woods (Ed.), Handbook of the clinical psychology of ageing. Chichester: Wiley.

Fowler, D., GARETY, P., \& KuiPers, E. (1998a). Cognitive therapy for psychosis: Formulation, treatment, effects and service implications. Journal of Mental Health, 7, 123-133. 
Fowler, D., GARETy, P., \& Kuipers, E. (1998b). Understanding the inexplicable: An individually formulated cognitive approach to delusional beliefs. In C. Perris \& P. D. McGorry (Eds.), Cognitive psychotherapy of psychotic and personality disorders: Handbook of theory and practice (pp. 129146.). Chichester: Wiley.

Genevay, R., \& KATZ, R. S. (1991). Countertransference and older adults. Thousand Oaks, CA: Sage.

Gumley, A. I., \& Power, K. G. (2000). Is targeting cognitive therapy during relapse in psychosis feasible? Behavioural and Cognitive Psychotherapy, 28, 162-174.

HANLON, R. B., TURK, D. C., \& RUDY, T. E. (1987). A collaborative approach in the treatment of chronic pain. British Journal of Guidance and Counselling, 15, 37-49.

James, I. A., Kendell, K., \& Reichelt, F. K. (1999). Conceptualizations of depression in older people: The interaction of positive and negative beliefs. Behavioural and Cognitive Psychotherapy, 27, 285-290.

John, C. H., \& TURKIngton, D. (1995). A model-building approach in cognitive therapy with a woman with chronic "schizophrenic" hallucinations: Why did it work? Clinical Psychology and Psychotherapy, 2, 1-16.

Kinderman, P., \& LobBAN, F. (2000). Evolving formulations: Sharing complex information with clients. Behavioural and Cognitive Psychotherapy, 28, 307-310.

KLEIFIELD, E. I., WAGNER, S., \& HALMI, K. A. (1996). Cognitive-behavioural treatment of anorexia nervosa. Psychiatric Clinical of North America, 19, 715-737.

KRANTZ, S. E. (1995). Chronic physical disability and secondary control: Appraisals of an undesirable situation. Journal of Cognitive Psychotherapy: An International Quarterly, 9, 229-248.

Krupnick, J. L., Sotsky, S. M., Elkin, I., Moyer, J., Watkins, J., \& Pilkonis, P. A. (1996). The role of the therapeutic alliance in psychotherapy and pharmacotherapy outcome: Findings in the National Institute of Mental Health treatment for depression collaborative research programme. Journal of Consulting and Clinical Psychology, 64, 532-539.

Laidlaw, K., Thompson, L. W., \& Gallagher-Thompson, D. (2004). A comprehensive conceptualisation of cognitive behaviour therapy for late life depression. Behavioural and Cognitive Psychotherapy, 32, 389-399.

Laidlaw, K., Thompson, L. W., Dick-Siskin, L., \& Gallagher-Thompson, D. (2003). Cognitive behaviour therapy with older people. Chichester: Wiley.

Layden, M. A., Newman, C. F., Freeman, A., \& Morse, S. B. (1993). Cognitive therapy of borderline personality disorder. Boston/London: Allyn \& Bacon.

LEAHY, R. L. (1999). Strategic self-limitation. Journal of Cognitive Psychotherapy: An International Quarterly, 13, 275-293.

LIESE, B. S. (1994). Brief therapy, crisis intervention and the cognitive therapy of substance abuse. Crisis intervention and time limited treatment, 1, 11-29.

Liese, B. S., \& LARSON, M. W. (1995). Coping with life-threatening illness: A cognitive therapy perspective. Journal of Cognitive Psychotherapy: An International Quarterly, 9, 19-34.

LINEHAN, M. M. (1993). Skills training manual for treating borderline personality disorder. New York: Guilford Press.

MoOREY, S. (1996). When bad things happen to rational people: Cognitive therapy in adverse life circumstances. In P. Salkovskis (Ed.), Frontiers of cognitive therapy. New York: Guilford Press.

Nelson, T. D. (2002). Ageism: Stereotyping and prejudice against older persons. Bradford Books.

PADESKY, C. (1993). Socratic questioning: Changing minds or guiding discovery. Keynote address to European Association of Behavioural and Cognitive Therapies. London, UK.

PADESKY, C. A. (1998). Protocols and personalities. The therapist in cognitive therapy. Paper presented at the European Association of Behavioural and Cognitive Therapies. Cork, Ireland.

PADESKY, C. (2002). Cognitive therapy unplugged: Fine tuning essential therapist skills. London Workshop. 
Padesky, C. A., \& Greenberger, D. (1995). Clinician's guide to Mind over Mood. New York/London: Guilford Press.

Rolland, J. S. (1989). Chronic illness and the family life cycle. B. Carter \& M. McGoldrick (Eds.), The changing family life cycle: A framework for family therapy (2nd ed.). Boston: Allyn \& Bacon.

Rybarczyk, B., Gallagher-Thompson, D., Rodman, J., Zeiss, A., Gantz, F. E., \& YeSAVAGE, J. (1992). Applying cognitive-behavioral psychotherapy to the chronically ill elderly: Treatment issues and case illustration. International Psychogeriatrics, 4, 127-140.

Safran, J. D., Segal., Z. V., Shaw, B. F., \& Vallis, T. M. (1990). Patient selection for short-term cognitive therapy. In J. D. Safran \& Z. V. Segal (Eds.), Interpersonal processes in cognitive therapy. New York: Basic Books.

SALMON, P. (2000). Psychology of medicine and surgery: A guide for psychologists, counsellors, nurses and doctors. Chichester: Wiley.

SANTROCK, J. W. (2002). Lifespan development (8th ed.). New York: McGraw-Hill.

STRAYER, J. (1987). Affective and cognitive perspective on empathy. In N. Eisenberg, \& J. Strayer (Eds.), Empathy and its development. New York: Cambridge University Press.

WALKER, D. A., \& ClARKE, M. (2001). Cognitive behavioural psychotherapy: A comparison between younger and older adults in two inner city mental health teams. Aging and Mental Health, 5, 197-199.

Woods, B., \& Charlesworth, G. (2002). Psychological assessment and treatment. In R. Jacoby \& C. Oppenheimer (Eds.), Psychiatry in the elderly (3rd ed.). Oxford: Oxford University Press.

YARHOUSE, M. A. (2000). Review of social cognition research on stereotyping: Application to psychologists working with older adults. Journal of Clinical Geropsychology, 6, 121-131.

ZeISS, A. M., \& LEWINSOHN, P. M. (1986). Adapting behavioural treatment for depression to meet the needs of the elderly. The Clinical Psychologist, 98-100. 